\title{
Design da Informação e Ciência da Informação: Contribuições e convergências nos estudos dos usuários
} Information Design and Information Science: contributions and convergences in user studies

\author{
Felipe Machado de Souza, Marli D. S. Pinto \& Francisco A. P. Fialho
}

usuário da informação, modelo metodológico, design thinking

\begin{abstract}
A informação tornou-se o insumo intelectual mais importante de nossa sociedade. Logo, é eminente o surgimento de áreas que passam a se ocupar da disseminação, armazenamento, acesso, seleção, organização e aprimoramento da informação. A Ciência da Informação e o Design da Informação são áreas que tem, além dessas ocupações, a incumbência de satisfazer os usuários e suas necessidades informacionais. Apesar disso, ambas não usufruem, de modo aprofundado, dos mesmos modelos metodológicos para o entendimento de tais necessidades. O presente artigo visa demonstrar a possível e exequível aproximação de ambas as áreas no que diz respeito aos estudos dos usuários da informação. Para isso, aplicou-se etapas do modelo mental dos designers, o design thinking, em uma prática realizada para os acadêmicos do Programa de Pós-Graduação em Ciência da Informação - PGCin/UFSC. Por meio de um questionário semiestruturado, consubstanciado pelos relados dos mestrandos e doutorandos, verificou-se, através de análise qualitativa, que os cientistas da informação consideraram o modelo metodológico eficaz e relevante para os estudos do usuário da informação.
\end{abstract}

\section{information user, methodological model, design thinking}

Information has become the most important intellectual input of our society. Therefore, the emergence of areas that are concerned with the dissemination, storage, access, selection, organization and improvement of the information is eminent. Information Science and Information Design are areas that have, besides these occupations, the task of satisfying users and their informational needs. In spite of this, both do not enjoy in depth the same methodological models for the understanding of such needs. This article aims to demonstrate the possible and feasible approximation of both areas with respect to studies of information users. For that, we applied steps of the mental model of the designers, the design thinking, in a practice realized for the academics of the Graduate Program in Information Science - PGCin/UFSC. Through a semi-structured questionnaire, based on the reports of the master's and doctoral students, it was verified through a qualitative analysis that information scientists considered the methodological model to be effective and relevant to the studies of the information user.

\section{Introdução}

A emergência e o avanço das Tecnologias de Informação e Comunicação (TICs), das mídias digitais e do ciberespaço têm alterado o modo como consumimos, buscamos e armazenamos as informações (Duarte, 2018).

Observa-se, no cenário atual, um crescimento exacerbado na quantidade de dados produzidos, disponíveis e disseminados nas esferas analógica e digital (Capurro \& Hjorland, 2007). Esses fatores tornaram a informação um dos fenômenos centrais da sociedade contemporânea, inclusive, originando termos e áreas específicas para seus estudos e aprimoramentos como a Sociedade da Informação, Sistemas de Informação, Marketing da Informação, Ciências da Informação, Design da Informação etc. Segundo as teorias dessas últimas duas, os ambientes e ferramentas virtuais vêm facilitando a busca pela informação, possibilitando preencher lacunas existentes nas estruturas do conhecimento. Porém, para preencher tais lacunas uma informação necessita ser de fácil acesso e interpretação e ainda satisfazer os usuários.

Anais do 9 $\mathrm{CIDI}$ e 9 CONGIC

Luciane Maria Fadel, Carla Spinillo, Anderson Horta, Cristina Portugal (orgs.)

Sociedade Brasileira de Design da Informação - SBDI

Belo Horizonte | Brasil | 2019

ISBN 978-85-212-1728-2
Proceedings of the 9th CIDI and 9th CONGIC

Luciane Maria Fadel, Carla Spinillo, Anderson Horta, Cristina Portugal (orgs.)

Sociedade Brasileira de Design da Informação - SBDI

Belo Horizonte | Brazil | 2019

ISBN 978-85-212-1728-2 
Devido aos fatores supracitados vem surgindo o reconhecimento da importância em entender as necessidades e motivações dos usuários no que tange a busca e uso de dados (Herrera, 2013; Capurro \& Hjorland, 2007). Tanto o design da informação, que como outras áreas do Design, concentram-se no usuário, quanto a Ciências da Informação, vem buscando compreender os indivíduos no centro das decisões informacionais para construir e projetar produtos, serviços, interfaces e unidades que os atendam plenamente.

O design da informação, explicita Katz (2012), se propõe a preparar organizar, transformar e apresentar as informações de modo a favorecer a apreensão do conteúdo de uma mensagem, tornando-a mais eficiente para os usuários. Já a Ciência da Informação analisa, coleta, classifica, armazena, recupera e dissemina a informação no seu sentido mais amplo (Capurro \& Hjorland, 2007). As duas áreas convergem em seus objetivos: solucionar os problemas dos usuários da informação. Contudo, nota-se que ambas não exploram com empenho as contribuições que uma pode proporcionar a outra, principalmente, no que diz respeito aos métodos para o entendimento das necessidades dos usuários.

Com base nesses pressupostos esse artigo tem como objetivo focal relatar a visão dos mestrandos e doutorandos sobre o uso do modelo mental dos designers para solucionar problemas dos usuários da informação na Biblioteca Universitária da Universidade Federal de Santa Catarina (BU/UFSC).

Como justificativa apresenta-se a aplicação simplificada do design thinking para demonstrar aos cientistas da informação como o design pode contribuir para aprofundar o entendimento dos usuários da informação.

O presente estudo demonstrou as vantagens do intercâmbio metodológico entre as áreas que visam à melhoria no acesso a informação. A abordagem do design thinking, para o entendimento do usuário da informação, pode contribuir para outros profissionais que buscam a mesma compreensão, como os cientistas da informação.

Metodologicamente, trata-se de um estudo exploratório que teve como participantes mestrandos e doutorandos do PGCin. Para a coleta de dados utilizou-se um questionário semiestruturado aplicado após as atividades da aplicação do design thinking. Para o tratamento dos dados, utilizou-se a abordagem qualitativa.

\section{Sociedade da Informação}

O presente estudo não tem o intuito de aprofundar conceitos da Sociedade da Informação. Contudo, como aborda duas esferas do conhecimento que adotam a informação como um tema substancial, entendeu-se ser importante apresentar um breve panorama da era informacional.

A Sociedade da Informação surgiu no século XX, segundo Duarte (2018), ela é consequência do momento evolutivo caracterizado pelos usos de recursos e tecnologias informacionais para a tomada de decisão. Nesse sentido, pode-se considerar a informação como a uma matéria-prima que otimiza e fundamenta a criação de Tecnologias de Informação e Comunicação (Werthein, 2000). Para Corrêa et al. (2014) a informação e as inovações tecnológicas passaram a ser determinantes para o desenvolvimento socioeconômico da sociedade ocidental, caracterizando nova acumulação capitalista e novo processo de globalização.

A informação tornou-se 'o insumo intelectual mais importante para o desenvolvimento das nações e do próprio indivíduo' (Duarte, 2018, p. 67). Logo, é compreensível entender que a informação desempenha, conforme explica Corrêa et al. (2014), importante função nos setores econômicos como também na vida pessoal, social, cultural e política.

Desse modo, é eminente o surgimento de disciplinas que passam a se ocupar da coleta, disseminação, armazenamento, acesso, organização, seleção e otimização da informação. Este artigo discorrerá sobre duas áreas expressivas que dão ênfase a essas questões, a 
Ciência da Informação e o Design da Informação. Ambas focam nas necessidades e motivações dos usuários no que tange a busca e interpretação da informação.

\section{Ciência da Informação}

A explosão informacional são discussões presentes nas pesquisas da Ciência da Informação (Cl) que é uma área do conhecimento que trata da análise, coleta, classificação, armazenamento, disseminação e recuperação.

Araújo (2014) sinaliza que a $\mathrm{Cl}$ engloba especialidades mais antigas como a Biblioteconomia e a Museologia, mas é considerada recente devido ao seu processo de institucionalização, ocorrida nas décadas de 1940 e 1950. Neste período, pode-se dizer que a $\mathrm{Cl}$ era uma disciplina que tinha o objetivo de investigar as propriedades e o comportamento informacional, as forças que governavam o fluxo de informação e os significados do processo da informação. Preocupava-se com à origem, coleta, organização, armazenamento, recuperação, interpretação, transmissão, transformação e utilização da informação em sistemas naturais e artificiais (Borko, 1968).

A evolução da área vem acompanhando os questionamentos e os modos de armazenar $\mathrm{e}$ disseminar a informação (Araújo, 2014). Ainda que a acima definição prevaleça, não é mais possível considerar, na atualidade, a $\mathrm{Cl}$ sem integrar as novas tecnologias. Logo, a área incorporou 'a geração, coleta, organização, interpretação, armazenamento, recuperação, disseminação, transformação e uso da informação, com ênfase particular, na aplicação de tecnologias modernas nestas áreas' (Capurro \& Hjorland, 2007, p. 186).

De acordo com Araújo (2014), as ciências da informação possuem algumas subáreas com focos em estudos distintos. Neste artigo, ressaltaremos os estudos referente aos usuários. Atualmente, essa subárea tem foco sobre as "práticas informacionais", voltadas para o estudo da ligação entre aspectos informacionais socioculturais e os comportamentos informacionais individuais (Araújo, 2014).

Os estudos dos usuários são investigações que os cientistas da informação fazem para saber o que os indivíduos precisam no que tange a informação (Figueiredo, 1994). Segundo Amaral (2013), o eixo dessa subárea está no conhecimento e identificação do fluxo, motivação, finalidade, demanda, satisfação e os efeitos da informação sobre o conhecimento. De maneira geral, os estudos dos usuários buscam verificar 'por que, como e para quais fins os indivíduos usam a informação, e quais os fatores que afetam tal uso' (Figueiredo, 1994 p. 7). Esses estudos 'são importantes para realizar uma 'ponte' como um canal de comunicação, entre os sistemas de informação e seus usuários, permitindo encontrar a melhor maneira de atender as suas necessidades' (Pereira et al. 2018, p. 110).

De acordo com os pesquisadores da área, há vários métodos utilizados para o entendimento dos usuários. Por muito tempo, quando o foco eram os sistemas, as metodologias possuíam bases quantitativas, mas, quando o comportamento do usuário tornouse relevante, os métodos qualitativos ganharam evidência (Pereira et at. 2018). Dentre os métodos qualitativos que se estabeleceram, nas últimas décadas, podemos citar: o Modelo Sense-Making, o Modelo de Kuhlthau, o Modelo de Ellis e o Modelo de Choo (Paletta, Brito \& Montanari, 2014; Pereira et at. 2018).

Mesmo que esses modelos já sejam utilizados para entender o comportamento informacional do usuário, este artigo propõe uma aproximação dos estudos dos usuários da $\mathrm{Cl}$ com os estudos dos usuários provenientes do Design. O intuito do artigo é explicitar aos cientistas da informação a propícia convergência entre as disciplinas. Pretende-se difundir o pensamento do designer, que tem como um dos principais objetivos compreender e solucionar os problemas dos usuários, seja referente ao uso de um produto, um sistema ou de uso da informação. 
Primeiramente, para demonstrar que as áreas têm pontos em comum, discorreu-se sobre o design da informação, uma das especialidades do design. Posteriormente, focaremos na abordagem do design thinking, o modelo mental do designer para solucionar problemas.

\section{Design da Informação}

De acordo com Flusser (2007), nossa sociedade vem perdendo o interesse em consumir coisas. Na atualidade, com o surgimento das tecnologias, o interesse no consumo tem migrado para o que ele designa de não coisas. "Essas não coisas são denominadas "informações" (Flusser, 2007, p. 54).

Logo, se o design - que na situação de verbo (to design), significa projetar, esquematizar, configurar - foi, por muito tempo, relacionado ao mundo material, agora, também, projeta/configura o mundo das não coisas, ou seja, das informações (ibid, 2007). Em outras palavras, além de atribuir forma a matéria o design atribui formas as não matérias, isto é, as informações.

O design serve, entre outras coisas, para solucionar problemas projetuais das não coisas. Nesse sentido, o design da informação pode ser considerado responsável por esses projetos, já que esta especialidade do design é entendida como a 'a arte de organizar, selecionar, otimizar e transformar dados complexos em informações mais fáceis, úteis e efetivas com a intenção de satisfazer as necessidades e objetivos do usuário de acordo com um contexto' (Herrera, 2013, p. 6).

Embora comumente relacionado ao design gráfico e ao processo de desenvolver mapas, infográficos e demais grafismos correlatos, fundamentados pela linguagem visual, o design da informação também é considerado um processo estrutural da informação em um sentido mais amplo (Katz, 2012; Carliner, 2000). Segundo Katz (2012), isso se dá porque o design da informação caracterizava-se por uma relação global e abrangente com o projeto, dando ênfase a capacidade de tornar informações complexas mais fáceis de serem entendidas.

Para Ferneda e Reis (2019) a literatura sobre design da informação ainda é incipiente e apresenta lacunas teóricas e conceituais. Os autores afirmam que não existe consenso bem definido sobre os seus limites e as áreas de atuação. Neste artigo, entendemos o design da informação de um modo amplo. Katz (2012) e Jorete (2016), acreditam que esta especialidade visa o processo de criação de espaços informacionais centrados nas necessidades dos sujeitos que interagem em/com ambientes. O design de informação prepara a informação de modo que seja facilmente assimilada pelos usuários. Ele tem como um dos principais propósitos 'transmitir informações para o usuário' (Katz, 2012, p. 17). O bom design da informação faz com que a informação seja acessível, apropriada, adequada, atrativa e compreendida pelo usuário (Quintão \& Triska, 2013).

O modo de expor a informação varia conforme o tipo de usuário. Por isso, é necessário saber fazer a seleção, a organização e a apresentação da informação de acordo com uma determinada audiência (Wildbur \& Burke, 1998). Portanto, entre 'os princípios que fundamentam a atuação do designer em um sistema de informação, o usuário é a figura central: todo projeto deve ser medido e avaliado a partir da perspectiva de suas necessidades e objetivos' (Souza et. al 2017, p. 163).

Por conseguinte, nota-se que o design da informação aproxima-se dos interesses da $\mathrm{Cl}$ sobre os estudos dos usuários. Logo, o modelo metal que o designer usufrui para a compreensão dos usuários pode contribuir aos cientistas da informação.

\section{O modelo mental dos designers}

Brown (2008) define design thinking como o modo dos designers verem e pensarem o mundo para conciliar as necessidades das pessoas, com o que é tecnologicamente exequível, 
convertendo-as em oportunidades e agregando valor. Resumidamente, o DT é uma ferramenta de inovação, uma abordagem de gestão, que se vale de técnicas e ferramentas que o designer usa para resolver problemas de uma forma inovadora (Ramirez \& Zaninelli, 2017).

Para Dune e Martin (2006), o DT é uma abordagem sistemática que apresenta os processos mentais utilizados pelos designers para projetar artefatos, serviços ou interfaces, como as da informação. Recentemente, praticantes e acadêmicos de diversas áreas tem se interessado pelo DT, porque querem explorar as estratégias de resolução de problemas desses profissionais e se beneficiar desse modelo para entender usuários e, ainda, gerar insights para a inovação. O trabalho dos designers é centrado no usuário, por essa razão, a maneira como eles pensam tornou-se demasiadamente importante para ficar apenas com os profissionais da área (Brown, 2010). Os cientistas da informação, por exemplo, já vêm utilizando esta abordagem como é possível averiguar nos estudos de Ramírez e Zaninelli (2017) e IDEO (2017), porém, ainda pouco disseminada ou compreendida pelos praticantes e acadêmicos da área.

Conforme Brown (2010) explica, o continuum da inovação (Figura 1), utilizado pelo DT, pode ser visto mais como um sistema de espaços que se sobrepõem do que como uma sequência de passos ordenados. É possível pensar da seguinte maneira esse sistema de espaços:

a inspiração, o problema ou oportunidade que motiva a busca por soluções; a idealização, o processo de gerar, desenvolver e testar ideias; e a implementação, o caminho que vai do studio de design ao mercado. Os projetos podem percorrer esses espaços mais de uma vez à medida que a equipe lapida suas ideais e explora novos direcionamentos (Brown, 2010, p. 16).

- Inspiração: Nesse momento, todos os profissionais envolvidos aproximam-se e imergem no contexto do problema do usuário. A partir de uma observação empática, nos contextos de uso, identificam-se problemas e coletam-se dados. Comumente são usadas técnicas como a observação participante, entrevistas etc.

- Idealização: As oportunidades observadas na inspiração são discutidas e refinadas, buscando a convergência de dados para gerar insights para o projeto. Técnicas de criatividade são frequentes nesse momento como, por exemplo, o brainstorming.

- Implementação: Com o conhecimento adquirido nas etapas anteriores propõe-se a prototipagem. Os protótipos materializam e colocam em prática as ideias geradas (Martins, 2016).

Figura 1: processo da abordagem do design thiking

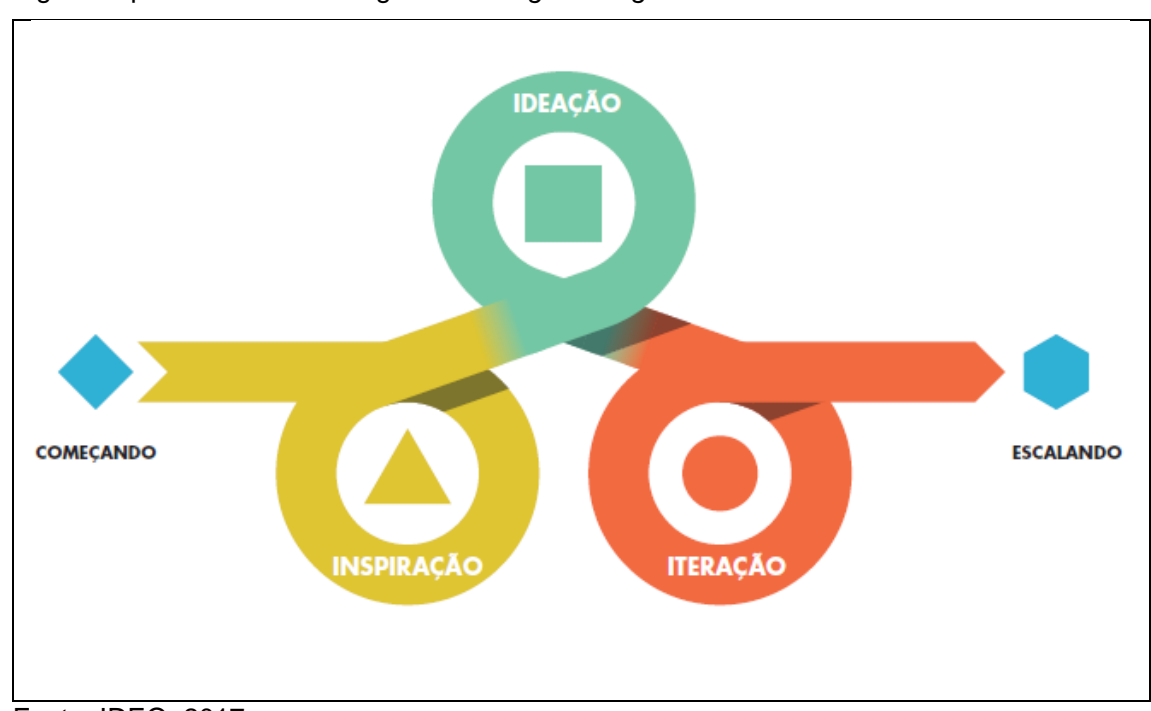

Fonte: IDEO, 2017. 
A missão do DT 'é traduzir observações dos usuários em insights, e estes em produtos e serviços para melhorar a vida das pessoas' (Brown, 2010, p. 46). Para tal tradução, a empatia é fundamental, pois dela surgem propostas para inovar e solucionar os problemas dos usuários. A empatia seria a tentativa de ver o mundo através dos olhos dos outros, de compreendê-lo por meio das experiências alheias (Brown, 2010). Essas experiências, por sua vez, podem prover diversos insights que são, posteriormente, tangibilizados no processo de implementação.

\section{Procedimentos metodológicos}

O estudo caracteriza-se como exploratório uma vez que buscou-se relatar a visão de mestrandos e doutorandos sobre o uso de técnicas e ferramentas do DT para solucionar problemas dos usuários da informação na Biblioteca Universitária da Universidade Federal de Santa Catarina (BU/UFSC).

Para elaboração do presente artigo foi efetivada uma revisão de literatura sobre a Ciência da Informação e sobre o Design da Informação, bem como a importância do entendimento dos usuários para ambos. Além disso, discorreu-se sobre o modelo mental dos designers, que vem sendo aplicada para solucionar os problemas de usuários, promovendo inovações.

Os pesquisadores do estudo são do Programa de Pós-Graduação em Design - PPGD. Já os participantes são alunos da disciplina Marketing e o usuário da Informação (mar./maio de 2019) do Programa de Pós Graduação em Ciências da Informação - PGCin, que fizeram uma prática para a compreensão do modelo mental dos designers. O intuito foi demonstrar aos nove mestrandos e doutorandos as vantagens de utilizar o DT como modelo metodológico para os estudos dos usuários da informação.

Além disso, a atividade objetivou apresentar o pensamento do designer aos cientistas da informação. Após a prática utilizou-se um questionário semiestruturado para verificar como o DT foi assimilado por esses acadêmicos.

Obviamente, não é novidade o uso do DT na $\mathrm{Cl}$, mas é bastante recente (Ramirez \& Zaninelli, 2017; IDEO 2017). Poucos pós-graduandos conheciam a abordagem ou já haviam praticado. A pesquisa de campo ocorreu na Biblioteca Central da UFSC, isso porque as bibliotecas possuem ampla necessidade de resolver os seus desafios informacionais, já que incluem: programas, espaços, serviços e sistemas (IDEO, 2017).

Inicialmente foi explicado aos participantes da disciplina, através de um workshop, o que é o DT e como ele pode cooperar para os estudos dos usuários. Posteriormente, clarificamos como todos deveriam proceder. Em seguida, apresentamos, por meio de uma cartilha (Figura 2), as técnicas e ferramentas que poderiam ser utilizadas pelos alunos na etapa de inspiração. As técnicas descritas e explicadas foram (IDEO, 2017):

- Observação (não) participante: revela os comportamentos reais. Observa-se tudo referente aos comportamentos: linguagem corporal, gestos, falas etc. A imersão gera empatia com os usuários.

- Jornada do usuário: mapeamento dos sentimentos e pensamentos dos usuários em diferentes pontos, ao longo do caminho percorrido no ambiente.

- Entrevistas com usuários ou especialistas: possibilita capturar necessidades e crenças dos usuários (ou de especialistas); é uma maneira de aprender várias informações sobre os problemas comuns.

Cada acadêmico selecionou uma das técnicas e aplicou no decorrer de uma semana com os usuários/especialistas da biblioteca. No encontro seguinte, usou-se a etapa da idealização, antes, porém, todos relataram suas reflexões e experiências com o campo; baseados nessa discussão iniciaram a segunda etapa: as sínteses e a geração de insights.

$\mathrm{Na}$ etapa da idealização, foram aplicadas as seguintes técnicas e ferramentas:

- Persona: servem como representantes de um grande grupo de pessoas reais. São 
construídas a partir de descobertas de pesquisa de campo, por meio de coleta de dados (Nunes \& Quaresma, 2018).

- Mapa da jornada do usuário: auxilia na estruturação da experiência do usuário em todo o trajeto realizado. Deve-se incluir momentos positivos, negativos e neutros na interação com o ambiente ao longo da jornada (Nunes \& Quaresma, 2018).

- Brainstorming: Técnica utilizada para geração de ideias criativas. Define-se um problema e a partir dele, em equipe, discute-se o maior número de ideias para uma solução em tempo cronometrado (Mazzotti, Broega \& Gomes, 2012).

Figura 2: Cartilha entregue aos mestrandos e doutorandos do PGCin, UFSC.

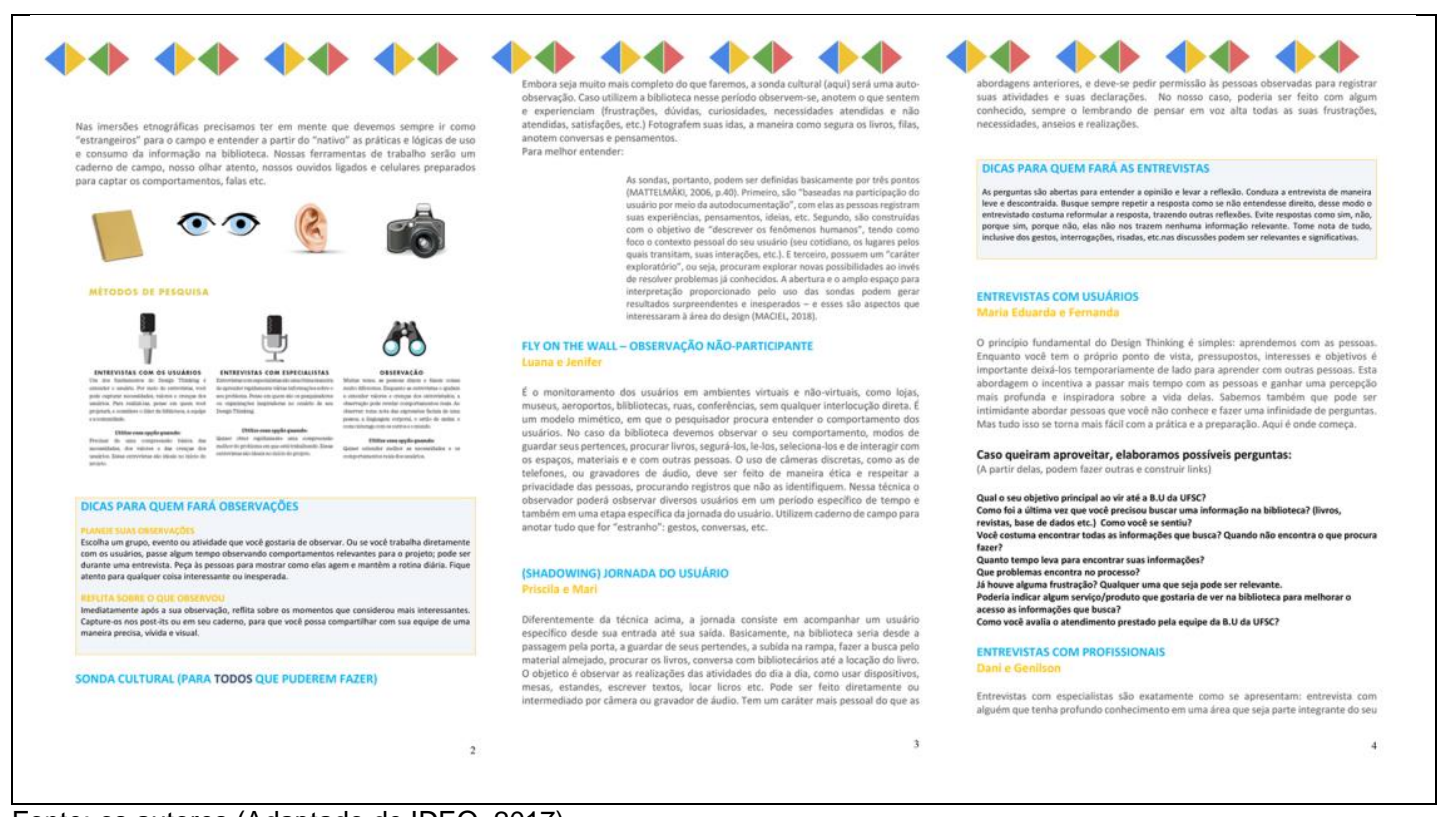

Fonte: os autores (Adaptado de IDEO, 2017).

A atividade focou especificamente nas duas primeiras etapas do DT, já que o intuito era dar uma introdução a abordagem. Logo, não adentramos a terceira etapa, a implementação. A seguir, discutiremos os resultados proveniente dos questionários para verificar como os cientistas da informação assimilaram as duas etapas do DT.

Esse estudo tem caráter exploratório, já que a amostra é pequena e permite uma melhor percepção dos problemas e das hipóteses levantadas (Honorato, 2004). E, por ter sido utilizado para a coleta de dados um questionário semiestruturado, consubstanciado pelo relato dos participantes, utilizou-se a análise qualitativa para o tratamento dos dados levantados.

Primeiramente, a qualitativa é frequentemente usada para análises de questionários, segundo, este tipo de análise não se apresenta rigidamente estruturada porque é considerada um meio para explorar e entender o significado que os indivíduos atribuem a um determinado problema (Creswell, 2010).

\section{Discussões dos resultados}

As perguntas iniciais do questionário tinham o propósito de compreender como os acadêmicos consideravam o estudo dos usuários para as ciências da informação. Além disso, buscou-se verificar se eles tinham conhecimento dos modelos metodológicos mais utilizados na área para esse objetivo. 
Todos, sem exceção, mencionaram ser primordial e relevante os estudos dos usuários. Segundo os alunos, por meio deles "é possível planejar e avaliar a qualidade dos serviços de uma unidade de informação" (Mestranda 2).

"Entender o usuário é importante para conhecer seu comportamento informacional, preferências e dificuldades no momento de buscar informação. Dessa forma, será possivel criar serviços, produtos e sistemas adequados para suprir suas necessidades informacionais.

Anteriormente sistemas de informação eram construídos sem muito input dos usuários, que eram forçados a se adaptarem aos sistemas. Atualmente, contudo, esse tipo de abordagem é considerado defasado e deve ser evitado" (Mestranda 5).

No que se refere-se aos métodos utilizados para o estudo dos usuários na $\mathrm{Cl}$, apenas uma mestranda mencionou desconhecer algum. Os demais citaram os principais (apresentados na revisão de literatura) ou outros provenientes do marketing. Foi enfatizado que cada método possui pontos positivos e negativos, e devem ser escolhidos conforme o ambiente informacional e os recursos disponíveis.

Dos seis respondentes dois relataram terem tido contato com o DT, e apenas um deles já havia colocado em prática, mas sem contato direto com os usuários. A partir das atividades ministradas, apresentaremos os feedbacks dos cientistas da informação sobre a prática do DT.

De maneira geral todos, mesmo que tenham considerado uma prática introdutória, adoraram o DT, considerando-o de grande serventia. Na etapa de imersão, onde tiveram contato direto com os usuários, destacaram:

- Vários elementos devem ser considerados na percepção do usuário;

- Cada acadêmico observou o usuário por uma perspectiva diferente; em alguns casos, notaram dores comuns a todos os usuários;

- A ótica que parte do próprio usuário;

- A possibilidade de verificar as dores dos usuários;

- O melhor entendimento sobre as dificuldades dos usuários e também do que está dando certo e, portanto, deve ser mantido.

Uma aluna do mestrado relatou a prática da imersão da seguinte maneira:

'As técnicas foram bem úteis para nortear a observação e a compreensão do usuário na sua relação com a biblioteca. Com isso, foi possível sair do papel de usuária e assumir a posição de investigadora, de alguém interessada em conhecer melhor a experiência do usuário a fim de torná-la mais satisfatória, seja por meio da oferta de outros serviços, do aperfeiçoamento de algum processo etc.' (Mestranda 3).

A prática ocorreu em dois momentos, inicialmente, orientamos os alunos como usar as técnicas de imersão durante uma semana na biblioteca. Posteriormente, aplicamos, durante 4 horas, algumas ferramentas e técnicas comumente usadas na segunda etapa, a idealização. A persona e a jornada do usuário proporcionaram aos mestrandos e doutorandos "clareza quanto às características dos usuários, no caso da persona, e à maneira como o usuário interage com os recursos e processos da unidade de informação, no caso a jornada na biblioteca" (Mestranda 3). Para eles a persona foi importante

'para se ter uma representação fácil de ser lembrada quando se for fazer o planejamento de um serviço ou produto. Serve para se perguntar "essa persona tem quais necessidades, como posso atende-la?" ou "esse serviço consegue resolver o problema dessa persona ou estamos gastando tempo e dinheiro com serviços que agregam muito pouco valor ao usuário?". O mapa da jornada foi importante para descobrir falhas e dificuldade ao longo da cadeia de procedimentos e ações que o usuário segue para utilizar a biblioteca. Auxilia a detectar pontos tortuosos da trajetória percorrida pelo usuário' (Mestranda 5).

Também foi explanado que as ferramentas proporcionaram clareza quanto às características dos usuários, no caso da persona; e entendimento da maneira como o usuário 
interage com os recursos e processos da unidade de informação, no caso a jornada.

Após a construção da persona e a análise da jornada do usuário, com o objetivo de convergir o que todos os pesquisadores observaram em campo, foi proposto um brainstorming. Diversas ideias emergiram nesse momento para solucionar os problemas encontrados e descritos anteriormente (Figura 3). Como não é nosso objetivo descrever tais ideias, relataremos os principais registros provenientes dos acadêmicos:

- A interação com os demais pesquisadores possibilitou conhecer diversas dores que os usuários possuem em relação a biblioteca; bem como aprofundar a compreensão sobre suas necessidades;

- Incentiva a colaboração e a criatividade entre os profissionais envolvidos no processo;

- Aponta várias soluções criativas para um mesmo problema, possibilitando pensar dentro de uma perspectiva da inovação.

- 'A prática focada na resolução de problemas por meio da proposta de apontar várias soluções para uma mesma situação instigou a criatividade e o planejamento em equipe' (Mestranda 5).

Figura 3: post-its com os insights da etapa de idealização.

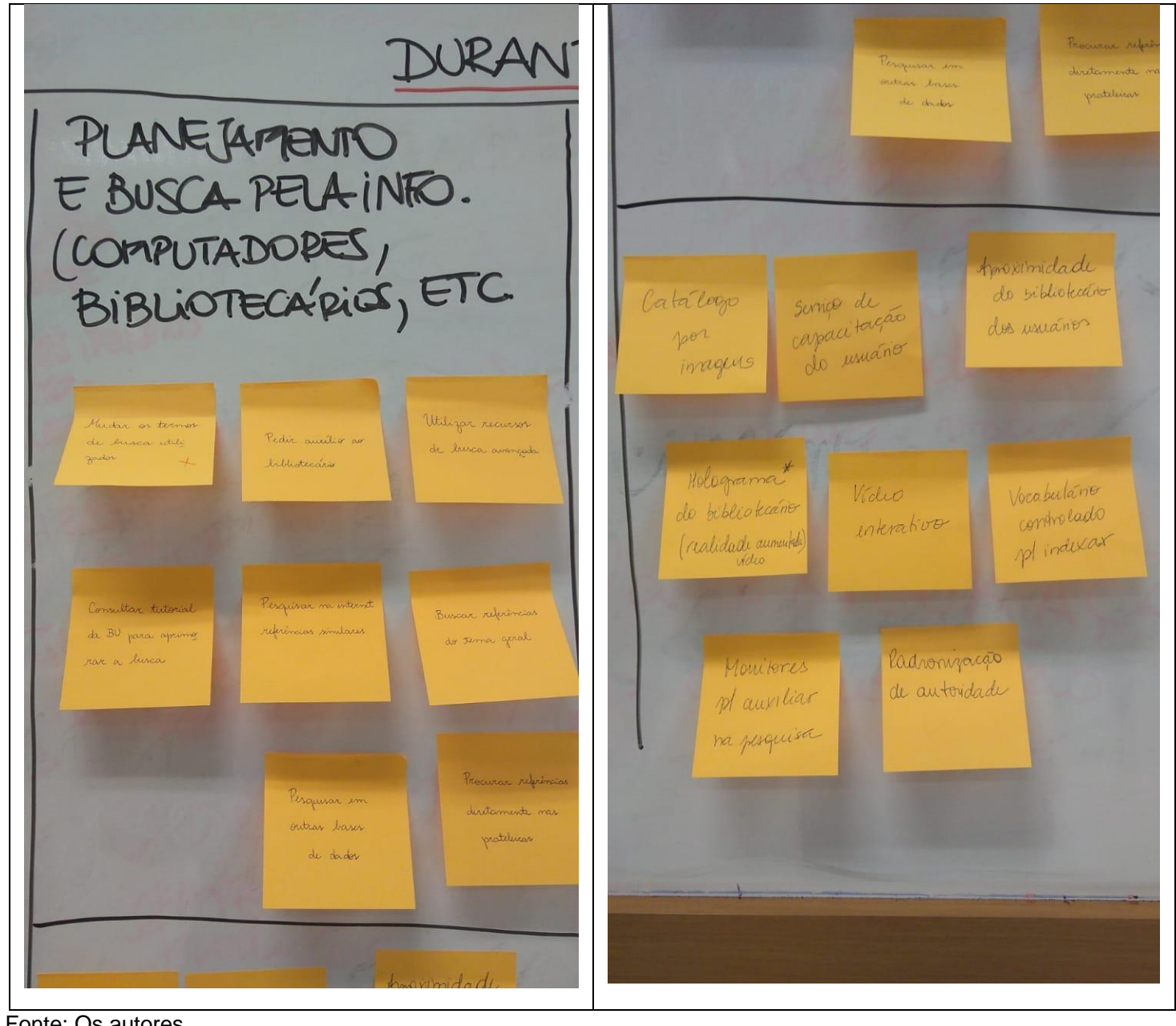

Fonte: Os autores. 


\section{Considerações finais}

A Ciência da Informação e o Design da Informação são áreas que tem, dentre seus objetivos, satisfazer os usuários e suas necessidades informacionais. Apesar disso, ambas não usufruem, de modo aprofundado, dos mesmos métodos e ferramentas para o entendimento das necessidades dos usuários.

O presente artigo objetivou demonstrar que é possível e exequível tal aproximação, em nosso caso, aplicamos o modelo mental dos designers, o design thinking, em uma prática realizada com os mestrandos e doutorandos do PGCin/UFSC.

A partir de uma pesquisa qualitativa, em que a coleta de dados foi realizada por meio de um questionário semiestruturado, verificou-se que os cientistas da informação consideraram a abordagem eficaz e de bastante relevância para os estudos do usuário da informação.

\section{Referências}

Amaral, S. A. (2013). Estudos de usuários e marketing da informação. Brazilian Journal of Information Science, (7) 3-25.

Araújo, C. A. A. (2014) O que é Ciências da Informação? Informação \& Informação, (19)1, 1-30.

Borko, H. (1968) Information Science: what is it? American Documentation (19)1, 3-5.

Brown, T. (2010). Design Thinking: Uma metodologia poderosa para decretar o fim das velhas ideias. Rio de Janeiro: Elsevier.

Capurro, R. \& Hjorland, B. (2007). O conceito de informação. Perspectivas em Ciência da Informação, (12)1, 148-207.

Carliner, S. (2000). Physical, cognitive, and affective: a three-part framework for information design. Technical communication, (47)4, 561-576.

Corrêa, C. A. R.. ROCHA, E. M. P., Carvalhais J. N. \& Dufloth, S. C. (2014). A sociedade da informação e do conhecimento e os estados brasileiros. Informação \& Informação, 19(1), 31-54.

Creswell, J. W. W. (2010) Projeto de pesquisa: métodos qualitativo, quantitativo e misto. Porto Alegre: Bookman.

Duarte, Y. (2018) Biliotecário do Século XXI. (Cap. 4. pp. 67-82). Brasília: Ipea.

Dune, D. \& Martin, R. (2006). Design thinking and how it will change management education: an interview and discussion. Academy of Management Learning \& Education, (5)4, 512-523.

Ferneda, E. \& Reis, M. C. A. (2019). Semiótica e o design da informação no desenvolvimento de objetos de aprendizagem. Ciências da Informação, (48)1, 23-40.

Figueiredo, N. M. (1994). Estudo de uso e usuário da informação. Brasília: Ibict.

Flusser, V. (2007). O mundo condificado: Uma filosofia do design e da comunicação. São Paulo: Cosac Naify.

Herrera, M. J. (2013, october) Toward a definition of information design. IEEE International Professional Communication Conference. Vancouver, BC, Canada.

Honorato, G. (2004). Conhecendo o marketing. Barueri: Manole.

IDEO. (2017). Design thiking para bibliotecas: um toolkit para design centrado no usuário. São Paulo: FEBAB.

Jorente, M. J. V. (2015). Tecnologia e design da informação: interdisciplinaridades e novas perspectivas para a Ciência da Informação. Bauru: Canal 6. 
Katz, J. (2012). Designing information: Human factors and common sense in information design. New York: Wiley.

Martins, A. R. Q., Signori, G. G., Capellari, M. R. S., Sotille, S. S. \& Kalil, F. (2016). Uso de design thinking como experiência de prototipação de ideias no ensino superior. Future Studies Research Journal, (8)1, 208-24.

Mazzoti, K., Broega, A. C. \& Gomes, L. V. N. (2012). A exploração da criatividade, através da técnica brainstorming, adaptada ao processo de criação em moda. I internacional fashion and design congress. Braga, Portugal.

Nunes, J. \& Quaresma, M. (2018). A construção de personas e do mapa da jornada do usuário: a delimitação de modelos mentais para o design centrado no usuário ou da interação usuário-notícia. Estudos em Design Revista, (26)2, 3-27.

Paletta, F. C., Brito, T. D. \& Montanari, T. A. (2014, novembro). Modelos de comportamento de busca da informação: Seu uso em pesquisas de estudos de usários. XVIII Seminário Nacional de Bibliotecas Universitárias - SNBU. Belo Horizonte, MG, Brasil, pp. 1-16.

Pereira, F. C. M., Jordão, R. V., Neto, M. C. C. \& Duarte, L. C. (2018). Estudos de usuário: Necessidades informacionais de empresas contratantes de pesquisa de mercado. Encontros Bibli: revista eletrônica de biblioteconomia e ciência da informação, (23)51, 10822.

Quintão, F. \& Triska, R. (2013). Design de informação em interfaces digitais: origens, definições e fundamentos. Revista Brasileira de Design da Informação, (10)2, 105-18.

Ramírez, D. M. B. \& Zaninelli, T. B. (2017). O uso do design thinking como ferramenta no processo de inovação em bibliotecas. Encontro Bibli: revista eletrônica de biblioteconomia e ciência da informação, (22)49, 59-74.

Souza, E. A., Oliveira, G. A., Miranda, E., Coutinho, S. G., Filho G. P. \& Waechter, H. N. (2017). A forma como conteúdo: o caso da Irma Boom. VIII Information Design International Conferenre - CIDI, Natal, RN, Brasil.

Werthein, J. A sociedade da Informação e seus desafios. Ciência da Informação, 29(2), 71-7.

Wilbur, P. \& Burke, M. (1998). Information graphics: Innovative solutions in contemporary design. London: Thames \& Hudson.

\section{Sobre o(a/s) autor(a/es)}

Felipe Machado de Souza, Doutorando em Design, UFSC, Brasil <mazafelipe@gmail.com> Marli Dias, Doutora, UFSC, Brasil <marlidiassp@gmail.com>

Francisco Fialho, Doutor, UFSC, Brasil <fapfialho@gmail.com> 